05

\title{
Взаимодействие наносекундного лазерного излучения с поверхностью монокристаллического титаната стронция
}

\author{
() И.С. Позыгун, ${ }^{1}$ Г.М. Серопян, ${ }^{1,9}$ И.Р. Султанов, ${ }^{1}$ С.А. Сычев, ${ }^{1}$ А.А. Теплоухов ${ }^{2}$ \\ ${ }^{1}$ Омский государственный университет им. Ф.М. Достоевского, \\ 644077 Омск, Россия \\ ${ }^{2}$ Омский государственный технический университет, \\ 644050 Омск, Россия \\ ๆ e-mail: ser_gm@mail.ru \\ (Поступило в Редакцию 19 декабря 2016 г.)
}

Работа посвящена проблеме формирования на поверхности монокристалла титаната стронция локальных модификаций структуры. В монокристалле создаются поля упругих механических напряжений при облучении сфокусированным наносекундным лазерным излучением.

DOI: 10.21883/JTF.2017.08.44738.2135

Титанат стронция $\left(\mathrm{SrTiO}_{3}\right)$ является прозрачным диэлектриком для видимого и ближнего ИК излучений. Поэтому можно применить теорию нетеплового механизма оптического разрушения прозрачных диэлектриков наносекундным лазерным излучением [1].

Лазерная модификация прозрачных твердых тел может быть связана с различными механизмами поглощения энергии лазерного излучения. Например, при воздействии сверхкоротких импульсов имеют место ударная и многофотонная ионизации, при воздействии длинных импульсов происходит интенсивное поглощение излучения дефектами материала. Реализация термического или нетермического механизма разрушения зависит от таких факторов, как длина волны излучения, длительность импульса, частота следования импульсов, плотность мощности излучения и др. Следует учитывать не только линейное поглощение лазерного излучения в однородном материале, но и механизмы, обусловливающие нелинейное поведение материала [2].

В прозрачных диэлектриках реализуются в основном следующие механизмы лазерного разрушения: тепловой (нагрев образца до плавления, возникновение термоупругих напряжений, термохимические процессы); фононный (генерация гиперзвука, оптических фононов, акустоупругих напряжений); связанные с несовершенством кристаллической решетки (дислокации, остаточные механические напряжения, примеси, которые всегда присутствуют в образцах); связанные с неоднородностью лазерного излучения и др. Однако расчеты чаще всего плохо согласуются с экспериментальными данными, что затрудняет выбор доминирующего механизма лазерного разрушения материала. В работе [1] механизм разрушения кристалла сводится к следующему: в фокальной области интенсивное лазерное излучение вызывает ионизацию, в результате чего возникает пространственно неоднородное облако горячих неравновесных электронов, приводящих к образованию в кристалле сильных полей механических напряжений. Возникновение напряжений и разрушение кристалла связано также с потоками импульса и энергии, переносимыми электронами из центральных областей фокального пятна к периферии. Рассеиваясь на примесях или дислокациях, такие потоки создают объемную плотность сил, деформирующих кристаллическую решетку. Если напряжения превысят предельно допустимые значения для данного материала, то образец разрушается. Автор работы рассматривает однородную упругую среду в сферической системе координат, где вводятся относительные смещения точек среды $u=u(r)$, тензоры деформаций и тензоры механических напряжений. Если на среду действуют силы, обладающие сферической симметрией и имеющие объемную плотность $F(r)$, то функция $u=u(r)$ должна подчиняться уравнению

$$
\frac{d}{d r}\left(\frac{1}{r^{2}} \frac{d}{d r}\left(r^{2} u\left(r^{2}\right)\right)\right)=-A F(r),
$$

где введенный постоянный множитель $A=\frac{(1+\mu)(1-2 \mu)}{E(1-\mu)}$ является функцией модуля Юнга $E$ и коэффициента Пуассона $\mu$.

В работе [3], используя граничные условия, получена плотность объемных сил, создаваемых неравновесными электронами в виде: $F(r)=\sigma_{i} n_{i} n_{e}(r) T_{e}(r)$, где $\sigma_{i}-$ сечение рассеяния электрона на одном дефекте решетки, $n_{i}$ - концентрация центров рассеяния, $n_{e}(r)-$ распределение концентрации горячих электронов, $T_{e}(r)-$ распределение температуры электронов.

В настоящей работе использовался твердотельный импульсный лазер с Nd:YAG-стержнем. Образцами служили монокристаллические пластины титаната стронция $\mathrm{SrTiO}_{3}(100)$ толщиной $0.5 \mathrm{~mm}$. Лазерное излучение имело длину волны $532 \mathrm{~nm}$, длительность импульса $12 \mathrm{~ns}$, энергию в импульсе $1 \mathrm{~mJ}$ и частоту следования импульсов до $50 \mathrm{~Hz}$. В ходе эксперимента варьировали скорость движения образцов относительно луча лазера и частота повторения импульсов, что позволяло менять дозу облучения поверхности. 


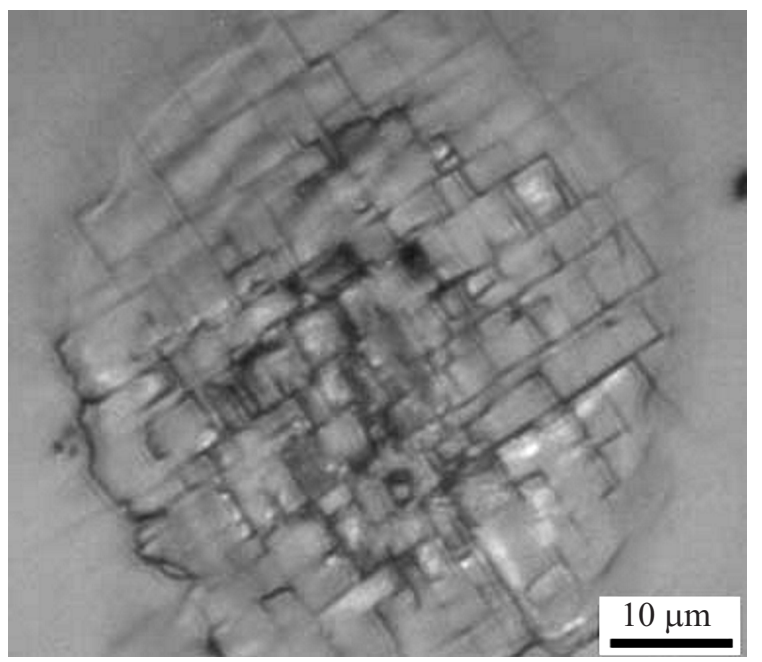

Рис. 1. Разрушение титаната стронция одиночным импульсом.

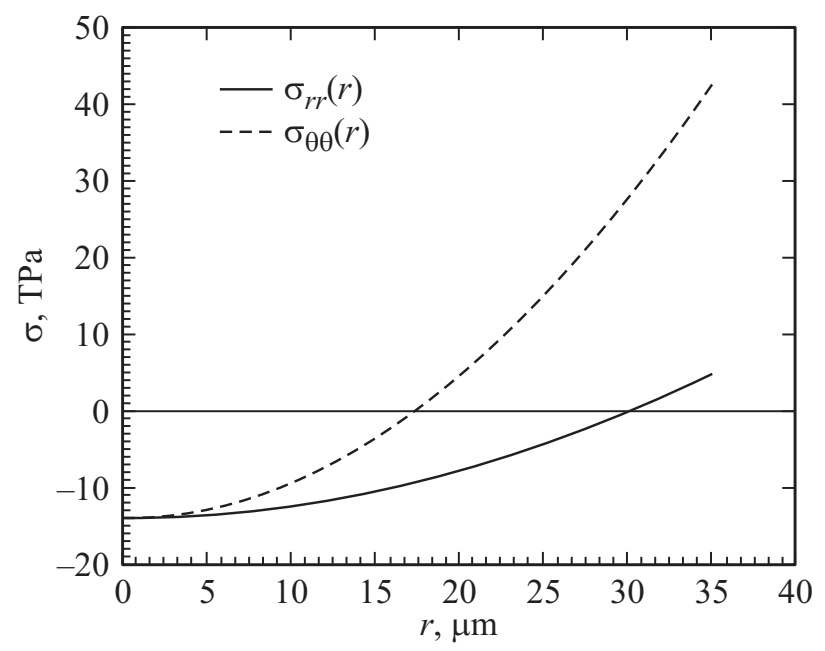

Рис. 2. Зависимости $\sigma_{r r}$ и $\sigma_{\theta \theta}$ от расстояния $r$ от центра пучка.

Экспериментально полученный порог разрушения (критическая плотность мощности) монокристалла $\mathrm{SrTiO}_{3}$ составил $4.8 \cdot 10^{8} \mathrm{~W} / \mathrm{cm}^{2}$. В экспериментах плотность мощности падающего лазерного излучения варьировали путем изменения площади лазерного пятна на поверхности образца путем соответствующей расфокусировки. При значениях плотности мощности лазерного излучения выше порога разрушения уже после первого импульса титанат стронция разрушается с образованием сети микродефектов. При этом энергия последующих импульсов эффективно преобразуется на этих дефектах в тепловую энергию кристалла. Микрофотография одноимпульсного разрушения поверхности титаната стронция представлена на рис. 1. Микротрещины на поверхности образца образуются вдоль кристаллографических направлений $a$ и $b$.

Для расчета компонент тензора напряжений $\sigma_{r r}$ и $\sigma_{\theta \theta}$ на малых расстояниях от центра пучка $r \leq \sqrt{2} a$ при его сильной фокусировке можно воспользоваться формулами из работы [4]:

$$
\begin{aligned}
& \sigma_{r r}(r, 0, \omega) \cong-\frac{\alpha_{t h} E W_{L}}{32 \sqrt{\pi} K_{S}} \frac{1}{a}\left(1-\frac{1}{1-\mu} \frac{r^{2}}{2 a^{2}}\right), \\
& \sigma_{\theta \theta}(r, 0, \omega) \cong-\frac{\alpha_{t h} E W_{L}}{32 \sqrt{\pi} K_{S}} \frac{1}{a}\left(1-\frac{1}{1-\mu} \frac{3 r^{2}}{2 a^{2}}\right),
\end{aligned}
$$

где $\alpha_{t h}=9.4 \cdot 10^{-6} \mathrm{~K}^{-1}-$ коэффициент теплового расширения, $K_{S}=12 \mathrm{~W} / \mathrm{m} \cdot \mathrm{K}$ (при $\left.300 \mathrm{~K}\right)-$ коэффициент теплопроводности, $E=3.03 \cdot 10^{11} \mathrm{~Pa}-$ модуль Юнга, $\mu=0.276-$ коэффициент Пуассона $[4,5]$. Импульсная мощность лазерного излучения $W_{L}=83 \mathrm{~kW}$, радиус сфокусированного лазерного пучка на поверхности образца $a=25 \mu \mathrm{m}$. Рассчитанные зависимости компонент тензора $\sigma_{r r}$ и $\sigma_{\theta \theta}$ от расстояния $r$ от центра пучка представлены на рис. 2.

Сравнение рассчитанных значений $\sigma_{r r}$ и $\sigma_{\theta \theta}$ с микрофотографией одноимпульсного разрушения на рис. 1 позволяет говорить о том, что микротрещины начинают исчезать при расстоянии $r=30 \mu \mathrm{m}$ от центра пучка, когда обе компоненты тензора принимают положительные значения.

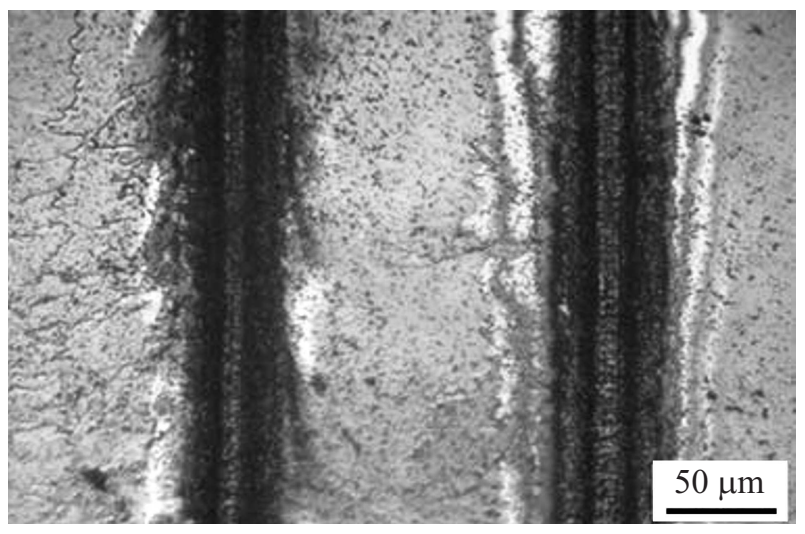

Рис. 3. Лазерный рез на титанате стронция при скорости перемещения 172 (справа) и $250 \mu \mathrm{m} / \mathrm{s}$ (слева).

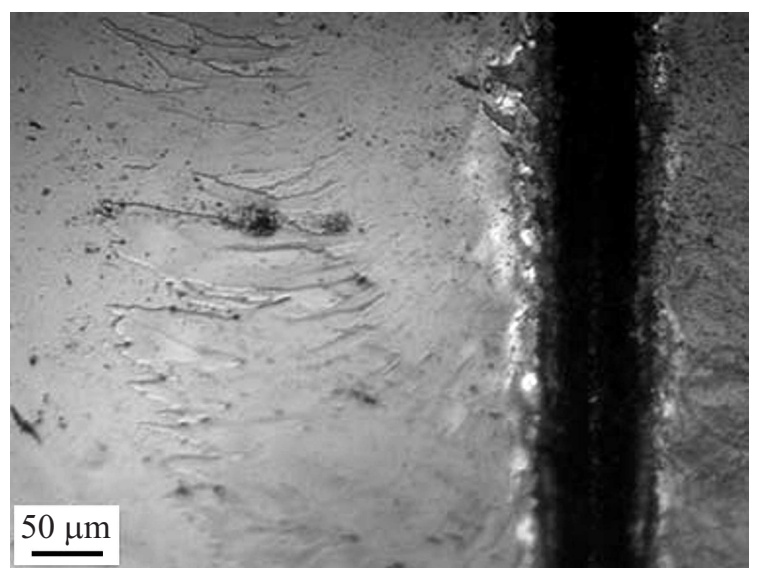

Рис. 4. Лазерный рез на титанате стронция при скорости перемещения $85 \mu \mathrm{m} / \mathrm{s}$. 
Изменение скорости перемещения лазерного луча при неизменных параметрах лазера и оптической системы позволяет менять дозу облучения поверхности образца. На рис. 3 и 4 изображены лазерные резы для разных скоростей перемещения. При самой высокой скорости перемещения наблюдается лишь оплавление по краям лазерного реза, а при самой низкой скорости ввиду более высокой дозы поглощенной энергии, приходящейся на единицу поверхности, в материале кристалла образуются области разрушения, которые значительно превышают ширину самого реза и могут достигать сотен микрометров. Для уменьшения размера напряженной области необходимо минимизировать дозу лазерного излучения, чтобы она была незначительно выше порога лазерного разрушения для данного материала.

\section{Список литературы}

[1] Стрекалов В.Н. // Письма в ЖТФ. 2000. Т. 26. Вып. 24. C. 19-20.

[2] Григорьяни, А.Г., Богданова М.А. // Наука и образование. 2012. № 3. C. 1-3.

[3] Стрекалов В.Н. // ЖТФ. 2002. Т. 72. Вып. 9. С. 75-79.

[4] Муратиков К.Л. // ЖТФ. 2013. Т. 83. Вып. 12. С. 155-158.

[5] Шаповалов В.А. // Физика и техника высоких давлений. 2010. T. 20. № 1. C. 56-61. 